$\begin{array}{ll} & \text { Etnográfica } \\ \text { etnográfica } & \text { Revista do Centro em Rede de Investigação em }\end{array}$ Antropologia

vol. 17 (1) | 2013

Vol. $17(1)$

\title{
Decifrando a cidade: sociabilidade e espaços públicos em São Paulo e Lisboa
}

Entrevista com Heitor Frúgoli Jr.

Graça Índias Cordeiro, João Pedro Silva Nunes, Lígia Ferro, Patrícia Pereira e Heitor Frúgoli Jr.

\section{(2) OpenEdition}

Journals

Edição electrónica

URL: https://journals.openedition.org/etnografica/2624

DOI: 10.4000/etnografica.2624

ISSN: 2182-2891

Editora

Centro em Rede de Investigação em Antropologia

Edição impressa

Data de publição: 1 fevereiro 2013

Paginação: 185-204

ISSN: 0873-6561

Refêrencia eletrónica

Graça Índias Cordeiro, João Pedro Silva Nunes, Lígia Ferro, Patrícia Pereira e Heitor Frúgoli Jr., «Decifrando a cidade: sociabilidade e espaços públicos em São Paulo e Lisboa», Etnográfica [Online], vol. 17 (1) | 2013, posto online no dia 13 março 2013, consultado o 11 fevereiro 2022. URL: http:// journals.openedition.org/etnografica/2624 ; DOI: https://doi.org/10.4000/etnografica.2624

\section{(c) (1) \$}

Etnográfica is licensed under a Creative Commons Attribution-NonCommercial 4.0 International License. 


\section{Decifrando a cidade: sociabilidade e espaços públicos em São Paulo e Lisboa}

\section{Entrevista com Heitor Frúgoli Jr.}

Por Graça Índias Cordeiro, João Pedro Silva Nunes, Lígia Ferro e Patrícia Pereira

Heitor Frúgoli Jr. é uma figura marcante na consolidação do diálogo em língua portuguesa em torno da prática da antropologia urbana. Professor do Departamento de Antropologia da Universidade de São Paulo, onde coordena o Grupo de Estudos de Antropologia da Cidade (GEAC), tem obra variada que é já uma referência nos estudos urbanos em português. As questões ligadas à sociabilidade urbana ${ }^{1} \mathrm{e}$ suas configurações no contexto dos espaços públicos ${ }^{2}$ e outros espaços de interação ${ }^{3}$ constituem o núcleo mais coeso da sua investigação, pois tem vindo a desenvolvê-las desde o início da sua carreira em diferentes contextos, como São Paulo e Lisboa. A investigação dos processos de constituição de novas centralidades em São Paulo, ${ }^{4}$ realizada no âmbito do doutoramento, complementa o seu olhar sobre a metrópole contemporânea. Desde 2006 que se tem aproximado de Portugal e da sociologia e antropologia urbana portuguesas, integrando a Rede Brasil-Portugal de Estudos Urbanos, ${ }^{5}$ cuja equipa portuguesa se encontra sediada na Universidade de Coimbra, coordenando um painel no último congresso da Associação Portuguesa de Antropologia (2009) e, mais recentemente, participando num conjunto variado de atividades no ISCTE-IUL, entre as quais o lançamento da edição em língua portuguesa de um dos mais recentes livros de Michel Agier, do qual é um dos revisores conceptuais. ${ }^{6}$ Aproveitámos uma das estadias de Heitor em Lisboa, na primavera de 2011 , para realizar esta entrevista. A conversa interrompeu por uma manhã o seu

I Heitor Frúgoli Jr., 2007, Sociabilidade Urbana, Rio de Janeiro, Jorge Zahar Editor.

2 Heitor Frúgoli Jr., 1995, São Paulo: Espaços Públicos e Interação Social, São Paulo, Marco Zero.

3 Heitor Frúgoli Jr. e Silvana Maria Pintaudi (orgs.), 1992, Shopping Centers: Espaço, Cultura e Modernidade nas Cidades Brasileiras, São Paulo, Ed. da Unesp.

4 Heitor Frúgoli Jr., 2000, Centralidade em São Paulo: Trajetórias, Conflitos e Negociações na Metrópole, São Paulo, Cortez/Edusp/Fapesp.

5 Rede originada no âmbito do Programa Comunidades dos Países de Língua Portuguesa (CPLP) do Conselho Nacional de Desenvolvimento Científico e Tecnológico (CNPq/Brasil).

6 Michel Agier, 201 1, Antropologia da Cidade: Lugares, Situações, Movimentos, São Paulo, Terceiro Nome (tradução de Graça Índias Cordeiro). O evento de lançamento em Lisboa ocorreu em maio de 201 I (organizado pelo CIES-IUL e Biblioteca do ISCTE-IUL) com o debate "Antropologia da cidade em língua portuguesa", no qual participaram, além do autor, pesquisadores portugueses e brasileiros. 


\begin{abstract}
trabalho de campo - no âmbito do qual tem contactado com novos e velhos residentes e comerciantes, notívagos e outros frequentadores do Bairro Alto - e o nosso próprio trabalho de preparação da "SICYurb: Second International Conference of Young Urban Researchers" (ISCTE-IUL, I 1-14 de outubro de 2011). O que agora se publica é apenas um fragmento de um diálogo que gostaríamos de continuar a ter por muitos e longos anos.
\end{abstract}

CORDEIRO, Graça Índias (graca.cordeiro@iscte.pt) - CIES-IUL, ISCTE - Instituto Universitário de Lisboa, Portugal.

NUNES, João Pedro S. (jplsn@iscte.pt) - DINÂMIA'CET-IUL, ISCTE - Instituto Universitário de Lisboa, Portugal.

FERRO, Lígia (ligia.ferro@iscte.pt) - CIES-IUL, ISCTE - Instituto Universitário de Lisboa, Portugal.

PEREIRA, Patrícia (patricia.pereira@fcsh.unl.pt), CESNOVA, Faculdade de Ciências Sociais e Humanas, Universidade Nova de Lisboa, Portugal.

GRAÇA ÍNDIAS CORDEIRO Gostávamos de saber como é que chegaste à antropologia urbana e aos temas que tens estudado. Sabemos que fizeste algumas incursões em várias cidades, que estás neste momento a fazer uma pesquisa em Lisboa, que nasceste e tens vivido em São Paulo. Pode-se dizer que São Paulo se impôs na tua vida?

HEITOR FRÚGOLI JR Eu nasci em São Paulo mas não vivi sempre ali. Na infância saí, fui viver em cidades do interior do estado e voltei para São Paulo na época da faculdade. Na verdade, fiz uma opção de faculdade equivocada e depois decidi, então, fazer o curso de ciências sociais na Universidade de São Paulo. Foi quando voltei para São Paulo, num momento particular em que ainda havia a ditadura militar no Brasil, em final dos anos 70. Apesar disso, São Paulo era uma cidade com uma efervescência cultural muito significativa: música, teatro, cinema. Então, essa decisão de fazer o curso de ciências sociais acabou por ser uma escolha de certo modo também política, não é? Quer dizer, foi o momento de entrar em contacto com um curso que tematizava a realidade sociocultural e, ao mesmo tempo, retomar também uma relação com São Paulo, no que ela tinha de metrópole. Eu tenho uma relação com São Paulo por ter nascido lá, mas o momento da faculdade foi uma espécie de retomada da cidade e isso tem um significado particular. E à medida que eu comecei a fazer a faculdade vários temas foram aparecendo, foram-se delineando como temas de interesse, até que num certo ponto comecei a voltar muito mais a minha atenção para a questão urbana e para a cidade.

GIC Antes propriamente da antropologia? 
HFJ Antes da antropologia. Num certo sentido, para mim a cidade era uma temática de interesse e de investigação, tanto que a primeira experiência de pesquisa que tive, um pouco mais detida, aconteceu no final da minha graduação, quando fiz o que chamamos no Brasil de iniciação científica. Foi uma pesquisa no largo da Concórdia, na cidade de São Paulo. Uma espécie de praça, mas uma praça peculiar no sentido que era um espaço encravado numa região quase central, com uma migração nordestina muito significativa e com usos informais do espaço: o comércio informal, a prostituição, entre outras coisas. Foi minha primeira experiência de pesquisa, que se dava no espaço de uma praça, de ruas, de interações que aconteciam nesse lugar. Lembro, inclusive, que logo no primeiro dia aconteceu uma espécie de drama social. Foi o que no Brasil que se chama de "rapa", ou seja, eu estava lá fazendo a pesquisa e chegou a polícia para apreender as mercadorias dos comerciantes informais, dos ambulantes. Aquilo foi uma fiscalização de grande porte e criou um conflito muito negativo...

GIC E tu estavas lá, no meio...

HFJ Eu cheguei ali e o que fiz, instintivamente, foi começar a anotar a coisas que aconteciam, não é? E logo na sequência fui abordado por algumas pessoas, como se eu fosse uma espécie de fiscal. E ao invés de eu começar a perguntar, eles começaram a me inquirir: o que estava fazendo ali e se eu era da polícia, se eu era da prefeitura e se eu era... E eu falei: "Não! Sou da faculdade, estou fazendo uma pesquisa e tal..." Quer dizer, foi interessante porque logo de cara já lidei com algumas questões que me fizeram aprender várias dimensões - até essa ilusão de iniciante de que a gente está invisível quando faz trabalho de campo. Foi interessante porque, à medida que eu fazia o trabalho no largo da Concórdia, ia-me deparando com uma questão, que era uma certa insatisfação com as teorias, sobretudo sociológicas de grande porte, para explicar aqueles aspetos que estavam se passando. Foi a partir daí que comecei a entrar em contacto inclusive com a teoria etnográfica e me interessei por estudar mais sobre essa questão da prática etnográfica.

GIC Esse era um trabalho final de graduação, uma espécie de mémoire de ciências sociais?

HFJ Não exatamente. O trabalho teve início numa disciplina optativa, de sociologia urbana. E foi algo que me levou a pensar na necessidade de construir algum tipo de aproximação disciplinar mais adequada para aquilo que estava efetivamente observando. Essa relação entre teoria e observação era um problema já presente para mim naquele momento específico. Então, acho que isso foi-se construindo passo a passo. Logo que terminei a faculdade tive uma experiência de trabalho na prefeitura, era uma assessoria. $\mathrm{Na}$ verdade, 
fazíamos visitas a inúmeras favelas em São Paulo. Não era uma pesquisa científica, era um trabalho, mas algo me chamou a atenção na época: a diversidade de contextos com que a gente deparava.

GIC Era um trabalho de apoio social?

HFJ Era um trabalho de levantamento sociodemográfico. Tinha uma intenção de mapeamento de alguns temas...

LÍGIA FERRO Já não estavam num contexto de ditadura nessa altura?

HFJ Ainda estávamos sob a ditadura, num período de redemocratização. Já havia eleições para o governo do estado, mas não para a presidência do país. Em meados dos anos 80 surgiu o movimento pelas eleições diretas, que foi muito expressivo, embora tais eleições só tenham ocorrido efetivamente em 1989...

Enfim, nessa experiência, o que me chamou a atenção foi uma enorme heterogeneidade de contextos para uma coisa que chamávamos de favela, mas que abrigava muitas situações. Quer dizer, aos poucos despertei para essa ideia de como alguns conceitos, às vezes, abarcam de forma muito totalizante algo e não levam em conta as diferenças. Retomando a pesquisa do largo da Concórdia: o que é uma praça? Quando se pensa numa praça, no senso comum é um espaço de encontro, de lazer, de contacto com a vegetação... O largo da Concórdia, nesse sentido, era uma "antipraça", atravessada por fluxos de trabalhadores, por um viaduto com automóveis, com toda uma utilização informal, etc. Foi quando resolvi fazer um mestrado em antropologia urbana e realizei a pesquisa sobre os shopping centers em São Paulo, ${ }^{7}$ com a orientação do professor José Guilherme Magnani. Era um tema que naquele momento me chamava a atenção: o crescimento dos shopping centers na cidade e o modo como esses espaços estavam se tornando lugares de interação para uma quantidade crescente de pessoas. Nesse momento específico, eu tinha interesse por esse tema da interação nos espaços públicos e os shoppings me despertavam uma certa curiosidade porque seriam espaços, num certo sentido, que "substituiriam" certos espaços públicos. Seriam espaços privados de acesso público, que passavam a ser frequentados por grande quantidade de pessoas e, naquele momento específico, também começavam a ser frequentados pelas classes populares. Fiz uma etnografia de três shoppings, comparando o Iguatemi, o Center Norte e o Morumbi, todos em São Paulo e que são shoppings com tipologias distintas: o Iguatemi era o primeiro shopping, ligado a um público de maior poder

7 Heitor Frúgoli Jr., 1992, "Os shoppings de São Paulo e a trama do urbano: um olhar antropológico”, em Heitor Frúgoli Jr. e Silvana M. Pintaudi (orgs.), Shopping Centers: Espaço, Cultura e Modernidade nas Cidades Brasileiras, São Paulo, Ed. da Unesp, 75-92. 
aquisitivo; na época, o Center Norte era um shopping que dava início a esse processo de massificação, abrangia regiões não necessariamente de maior poder aquisitivo; e um shopping intermediário, o Morumbi, ao mesmo tempo que abrangia públicos de grande poder aquisitivo, também incorporava classes populares de algumas áreas. Então, naquele momento, desenvolvi uma pesquisa justamente sobre essa temática da interação, dado que também os shoppings eram apresentados, na época, como se fossem espaços totalmente fechados, um pouco parecidos com o modelo do condomínio fechado. Na verdade eu discordo desse tipo de aproximação. Embora você possa até ver certa similaridade entre ambos, eles são espaços, num certo sentido, distintos.

Então, gradativamente fui-me interessando pelo tema da cidade e, ao mesmo tempo, percebendo que o modo como eu fazia certas perguntas, o modo como eu investigava, passava muito por uma relação com a antropologia e com a antropologia urbana.

LF Como é que você deu o salto dos estudos dos shopping centers para o bairro da Luz, a "cracolândia"?

HFJ Existem questões recorrentes, como, por exemplo, os temas da interação, da sociabilidade, do espaço público, mas há também ruturas, buscas marcadas por interesses um pouco distintos. Depois de fazer a pesquisa sobre os shopping centers, no meu doutorado voltei-me a uma discussão na área da sociologia urbana, para pensar a questão da centralidade de São Paulo. Nesse momento estava um pouco insatisfeito, quer dizer, já tinha feito vários trabalhos a partir de contextos, digamos, mais “microscópicos". Na época que desenvolvi a pesquisa sobre centralidade, fiz um pouco o caminho inverso, pois queria a princípio pensar questões mais abrangentes, mas acho que implicitamente acabei por desenvolver uma pesquisa empírica com determinados agentes. Nos anos 90, em São Paulo, começou a aparecer de forma mais significativa a questão da revitalização das zonas centrais. Logo depois, apareceu o tema da requalificação e esses temas se desdobraram e ganharam muita visibilidade, em meados dos anos 90. Eu me interessei por investigar isso, com enfoque no tema da centralidade. Isso porque em São Paulo, nessa época, por um lado, o centro histórico passava por um processo de renovação, por intervenções urbanas pontuais que tentavam redefinir esse espaço; por outro, a grande imprensa ressaltava a região em torno da avenida Paulista, que abriga edifícios ligados ao setor financeiro e patronal, além de museus e outras instituições, como uma espécie de "novo centro" de São Paulo, principalmente quando esta fez 100 anos, em 1991. No entanto, tal apogeu foi rapidamente seguido por sinais de decadência, e a imprensa logo passou a falar de um outro espaço, delimitado pela avenida Luis Carlos Berrini, com dezenas de edifícios de escritórios construídos por uma única empresa, e pela avenida Marginal Pinheiros, próxima dali, 
marcada pela existência de vários edifícios de multinacionais. Essa área veio também a ser chamada de "o novo centro de São Paulo".

Então, tal pesquisa levou-me a aproximar das associações representativas de cada uma dessas regiões que estavam, num certo sentido, concentrando um certo discurso a respeito desses espaços em São Paulo. A associação Viva o Centro, naquele momento, tentava interferir na opinião pública sobre o que era o centro, quem devia ocupá-lo, que processos deviam acontecer nesse espaço. Ao mesmo tempo, no outro polo, na avenida Berrini, também havia grupos empresariais e associações com o poder público, que tentavam legitimar aquele local como um espaço de maior investimento em função dos negócios e tudo o mais. Então procurei, na verdade, comparar esses três espaços e os discursos acionados por essas organizações. Depois de terminar esse trabalho, eu continuei a me interessar pela questão urbana, mas novamente retomei um contacto maior com a antropologia. Na verdade, quando fiz essa pesquisa sobre centralidade, tive a oportunidade de fazer um doutorado "sanduíche" ${ }^{8}$ na Universidade da Califórnia, em San Diego. E lá tive uma relação muito significativa com antropólogos que trabalhavam com a questão urbana. Quer dizer, eu continuara com essa questão da antropologia presente. O facto é que, quando terminei o doutorado, me voltei novamente para a antropologia e comecei a trabalhar, a dar aulas em antropologia, e esse campo voltou a ser de grande interesse, até eu chegar à questão do bairro, uma dimensão que tenho estudado um pouco mais: no caso, o bairro da Luz, em São Paulo, e o Bairro Alto, em Lisboa. Como configurar antropologicamente ou etnograficamente um bairro? O que é um bairro, como é que ele pode ser pensado, como se pode fazer uma etnografia a respeito desses espaços? E a ponte que existe com os trabalhos anteriores é que são bairros situados em áreas centrais. Eu acho que essa é uma dimensão que está muito presente no meu trabalho.

LF Quando o Heitor diz que no doutoramento se aproximou mais da sociologia, isso quer dizer que a temática da sociabilidade estava menos presente nesse trabalho?

HFJ Sim. Na verdade, acho que me aproximei mais da sociologia, a princípio porque estava preocupado em circunscrever, naquele momento, questões mais abrangentes que não passavam tanto por um exame etnográfico mais detido. E a investigação naquele momento estava mais ligada à prática da entrevista do que propriamente àquilo que observava no campo. Implicitamente eu tinha questões que observava, que me chamavam a atenção, mas às quais eu não dei maior relevo porque a preocupação era outra. Hoje já não tenho interesse em

8 Doutorado "sanduíche" é o nome dado, no Brasil, ao programa de doutoramento parcialmente realizado numa universidade estrangeira. 
desenvolver isso. É mais comum que eu tente articular a observação com, eventualmente, a entrevista. Quase que dá para dizer que hoje a entrevista ocupa um lugar cada vez menor. Não que ela não deva existir, mas ela só deve acontecer depois de você ter amadurecido outras questões ligadas à observação.

GIC Sobre esta relação entre a sociologia e a antropologia, pões, de certa forma, a antropologia do lado da observação e a sociologia mais do lado da entrevista, mas eu estou a ver a coisa pelo teu percurso do shopping à centralidade e agora ao bairro. Para além de achar um processo muito interessante, também vejo aqui um jogo de escalas. Quando vais fazer o doutoramento em sociologia é porque sentes que a centralidade está numa escala de fenómenos em que a antropologia não vai lá, não chega lá? Não será também um problema de escala, esta relação entre a antropologia e a sociologia? E não continuarás com este problema de escala, agora que estás a estudar um bairro?

HFJ Eu acho que hoje, com base nos meus trabalhos mais recentes, essa questão da escala se coloca de um outro modo. A escala é uma questão que também pode ter um tratamento etnográfico. Durante muito tempo eu fiquei ligado a essa dimensão do microscópico e do macroscópico e, num certo sentido, relacionava perspetivas disciplinares mais afeitas para um ou para outro plano. Acho que, hoje, isso se coloca de uma outra maneira. Eu entendo que, do ponto de vista antropológico, você pode trabalhar com distintas escalas, dependendo do modo como você confere, àqueles que você pesquisa, uma dimensão ou outra. Por exemplo, na pesquisa que estou desenvolvendo hoje no Bairro Alto, é possível prestar atenção ao plano local, pois existem certas ruas nas quais tenho feito uma etnografia mais detida, com observação do que acontece ali entre as pessoas, ao passo que, com outros agentes com quem tenho contacto, eles têm-me mostrado dimensões mais abrangentes, que envolvem outros planos da cidade e aí se pode, a partir de certas escolhas, começar a entender como essas pessoas situadas num determinado espaço se apropriam de uma forma mais abrangente da cidade. E com isso, essa relação entre o micro e o macro se redefine. Eu concordo com você, mas acho que a gente tem de prestar atenção, na hora da etnografia, ao princípio de variação de escala. ${ }^{9}$ Só que eu acho, por outro lado, que sempre existe uma escolha no modo como você amplia ou situa isso, porque os seus agentes podem vir a mostrar dimensões muito abrangentes. Num certo sentido, podem fazer "explodir" o seu objeto. Então, acho que existe uma dimensão de escolha, que depende do modo como você orienta o seu interesse. Por exemplo, nessa minha pesquisa atual, podem-se eleger questões mais locais no sentido de interações que acontecem num dado

9 Ver, a respeito, Bernard Lepetit, 1998, "Sobre a escala na história”, em Jacques Revel (org.), Jogos de Escalas: A Experiência da Microanálise, Rio de Janeiro, Ed. FGV, 77-102. 
espaço. Por exemplo, um tema que tem aparecido às vezes no meu trabalho é a relação entre portugueses e brasileiros. Você tanto pode tentar entender como isso se dá num espaço específico, como isso ocorre, como você pode também, a partir de certas falas, ver como essas redes se expandem para contextos mais abrangentes. Mas aí facilmente pode virar uma outra pesquisa, não é? Você pode tomar, por exemplo, um brasileiro no Bairro Alto e ver como ele constrói certas relações cotidianas locais ali ou mesmo em Lisboa. Mas a partir de certas falas, também se poderia começar a pensar o modo como ele reconstitui as redes ligadas ao Brasil. Por isso, nesse caso específico, tenho tentado fazer uma abordagem de interações numa perspetiva mais intensiva e nem tanto extensiva (embora entre intensivo e extensivo também haja algo que você precisa dosar e ver como enfrenta). É um desafio, uma dimensão importante. Acho que uma outra, quando você fala da relação entre sociologia e antropologia, tem a ver com a questão do significado da etnografia para essas duas disciplinas. ${ }^{10}$ Quer dizer, eu venho de uma formação, de um determinado tipo de antropologia onde o diálogo com a sociologia e a ciência política foi bastante significativo, se pensarmos em Eunice Durham, em Ruth Cardoso e nas pessoas que vieram desse tipo de orientação. Havia uma espécie de diálogo que eu sempre considerei frutífero, tendo a etnografia como uma espécie de polo de tensão positivo, ou seja, quando você começa a teorizar demais, os dados etnográficos podem mostrar uma outra coisa. Ainda mais porque acho que não se pode ficar com essa ideia de que a antropologia tem o monopólio da prática etnográfica, na medida em que existem outras disciplinas que também a fazem. De toda forma, temos que pensar também em como cada disciplina incorpora a etnografia no seu fazer teórico. Acho que a antropologia tem uma especificidade de dar mais espaço àquilo que se encontra etnograficamente, enquanto outras disciplinas, talvez alguns setores da sociologia, tendem a controlar um pouco mais esses impactos. Num certo sentido, eu diria que hoje tento fazer uma etnografia mais antropologicamente orientada.

GIC No fundo, a relação entre etnografia e teoria tem mais espaço na antropologia, do que, eventualmente, na sociologia...?

HFJ Sim, ainda mais porque, de um certo ponto de vista da antropologia, nem faz muito sentido você separar etnografia e teoria, pois elas estão articuladas. Só que esse campo de diálogos entre antropologia e sociologia é, pelo menos no Brasil, muito tensionado. Ou seja, aquilo que havia de interlocução entre antropologia e sociologia, hoje acho que é um diálogo mais áspero e muito

10 Heitor Frúgoli Jr., 2005, "O urbano em questão na antropologia: interfaces com a sociologia”, Revista de Antropologia, 48 (1): 107-124. 
mais difícil. O diálogo interdisciplinar é sempre áspero, mas acho que hoje ele está particularmente...

GIC Mais áspero do que há 20 anos?

HFJ Mais, mais... Eu acho, por exemplo, que para as gerações mais recentes de antropologia, a sociologia não é uma referência significativa, pelo contrário, passa a ser uma ciência, uma disciplina muito rejeitada. E é preciso lidar com isso também no modo como me relaciono com meus orientandos. Claro que, pessoalmente, hoje começo a me interessar cada vez mais por uma aproximação com outras áreas da própria antropologia. Mas, enfim, tenho uma relação, uma história com isso.

JOÃO PEDRO SILVA NUNES Regresso à escala dos bairros e à escala da observação. Lendo Espaços Públicos e Interação Social e Centralidade em São Paulo, uma das questões que ressalta é a da diversidade de populações e de grupos - da população sem-abrigo, aos vendedores ambulantes, no largo da Concórdia, passando pelos porta-vozes do que deve ser o centro da metrópole. Como é que o Heitor lê esta relação entre grupos e espaços na grande cidade e como é que, na pesquisa, faz jogar esta transversalidade metropolitana?

HFj Acho que esse é um dos desafios de trabalhar sobretudo com bairros, com situações ou com agentes situados nessas áreas, digamos, mais centrais. Isso é importante pontuar porque existe uma tradição, pelo menos em São Paulo, mais voltada a trabalhar, por exemplo, com bairros situados em áreas periféricas. A periferia como um tema de interesse significativo é algo que se firmou bastante em São Paulo. Ao passo que no Rio, por exemplo, existe uma certa tradição de trabalho com favelas, ainda que no Rio, na área da antropologia urbana, tenha havido também uma dimensão mais voltada, por exemplo, às camadas médias urbanas, por influência de Gilberto Velho, um olhar para outras áreas que não as favelas. Mas existe uma certa tendência em trabalhar com aquilo que estaria "fora da cidade", por estar sem os equipamentos, sem os direitos, etc. Isso é importante, mas há uma outra dimensão, que é justamente não o que se separa da cidade, mas o que constituiria a cidade nas suas várias dimensões. Talvez eu venha enfrentando um pouco essas dimensões quando trabalho com esses temas que você sublinhou.

Penso também nas múltiplas determinações que nós pesquisadores definimos de uma forma contextual e apriorística. Daí o desafio, numa aproximação sucessiva com esses agentes, de entender o que efetivamente está em causa para eles, quais são suas questões, como é que essas perguntas se redimensionam. Às vezes, por exemplo, a noção de bairro é algo que acionamos mas que não é significativa para os nossos agentes. Outras vezes, não achamos que sejam 
importantes, mas eles acionam. Também tenho tentado prestar muita atenção ao modo como esses grupos, na verdade, ressignificam aqueles conceitos que nós, a princípio, achamos que seriam importantes. Por exemplo, no caso de São Paulo começamos a eleger o chamado bairro da Luz como uma temática. Mas não existe nada mais escorregadio do que essas noções de bairro naquele caso específico, porque as fronteiras são múltiplas. Existem fronteiras com o Bom Retiro, a Santa Efigénia, os Campos Elísios... ${ }^{11}$ A ideia de bairro nesse caso não se sustenta muito, os agentes recorrem a identificações que são múltiplas. Portanto, é comum que iniciemos com certa referência, para depois entendermos como os agentes pesquisados impactam essa dimensão. Não sei se eu respondi...

JPSN Respondeu, sim. Outro aspeto que também me parece muito significativo é o facto de boa parte dos contextos urbanos que o Heitor tem estudado terem sempre presente o trabalho, embora não necessariamente colocado por si como problema de pesquisa. Para além de os seus interlocutores em situação de observação trabalharem na cidade, de ser na cidade que têm os seus meios de vida e que as suas relações com os outros se espacializam, parece também haver como que um trabalho de levantamento acerca do que é ou não problemático para os urbanitas nas suas zonas de interesse. Como vê, na sua pesquisa, esta dimensão do fabrico da cidade pelos seus habitantes?

HFJ No geral, acho que a dimensão do trabalho é uma dimensão importante mas não sei se seria sempre a dimensão determinante. Por exemplo, na pesquisa sobre o largo da Concórdia, a ideia da praça como espaço de encontro, lazer e sociabilidade era negada na prática por aqueles que ocupavam aquele local para práticas de trabalho. Os engraxates com quem tive contacto na época, que eram quase todos nordestinos, concebiam aquele espaço de uma forma bastante peculiar, como se fossem "uma pequena empresa". Já na pesquisa sobre os shopping centers, minha preocupação era justamente sobre o consumo e o lazer. Essa dimensão não estava muito presente, embora ela aparecesse como pano de fundo, para os lojistas. Mas acho que estou sempre tentando confrontar múltiplas determinações que se entrelaçam. Na pesquisa sobre o Bairro Alto, também aparece um pouco essa dimensão. Você tem, por um lado, uma série de grupos e de pessoas que usam aquele espaço para lazer, ao mesmo tempo que ali os donos dos bares ou dos estabelecimentos pensam aquilo do ponto de vista do rendimento, do trabalho. É importante frisar que às vezes a gente tende a identificar, por exemplo, um ator social como ligado ao mundo do trabalho mas na pesquisa se percebe que essas identificações se multiplicam, se fragmentam.

JPSN E a cidade permite ler isso, não é? 
HFJ Exatamente. Às vezes você começa a lidar num local com a identidade de moradores, só que você aos poucos percebe que um morador também é alguém que se move por determinados espaços. Aí a questão da situação predomina, ou seja, a depender do contexto situacional, a pessoa pode acionar algum outro tipo de identificação onde às vezes a questão do trabalho perde o relevo e noutras, ganha. Tudo depende da situação que você enfoca e daquilo a que você presta mais atenção.

PATRÍCIA PEREIRA De São Paulo para Lisboa: o que o atraiu em Lisboa e no Bairro Alto em particular?

HFJ Minha vinda para Lisboa foi, primeiro, ocasionada por atores institucionais. Eu faço parte da Rede Brasil-Portugal de Estudos Urbanos, que propicia o intercâmbio entre pesquisadores brasileiros e portugueses. Isso permitiu que eu viesse a Portugal e pudesse começar a eleger alguns sítios para desenvolver pesquisa. E dentro dessa preocupação de trabalhar com bairros situados em áreas centrais, com um conjunto significativo de determinações e questões, o Bairro Alto me chamou a atenção como espaço de possível aprofundamento. Fiz algumas vindas para cá, mas sempre muito pontuais. Aí, por conta própria decidi, com uma bolsa da FAPESP, ${ }^{12}$ ficar em Lisboa por alguns meses, para acumular um conhecimento mais aprofundado, não só do bairro mas do contexto mais abrangente, da inserção do bairro numa cidade específica, numa sociedade específica. E é isso que estou fazendo agora, trabalhar de forma mais detida e pela primeira vez num contexto, digamos, mais distanciado, porque minhas pesquisas em geral estavam localizadas em São Paulo...

PP Em casa, não é?

HFJ Exatamente, em casa. Já fiz pesquisas fora de São Paulo, mas com uma certa proximidade. Acho que Lisboa me insere um pouco em algo presente na antropologia, que é você se deslocar significativamente do lugar ao qual está habituado, no caso, ir "além-mar". Ao passo que é também interessante porque o facto de estar em Lisboa traz novamente outras ilusões, porque você pensa: "Bom, eu falo português, e eles também; então, num certo sentido, temos alguma coisa que nos aproxima". Mas isso pode ser ilusório. Há um bar que tenho frequentado no Bairro Alto. É, ao mesmo tempo, uma casa de pasto, depende do horário. Mas há um momento em que as pessoas se reúnem ali e são pessoas das classes populares, que conversam entre elas, com piadas que eu capto muito pouco. E eu também não posso ficar pedindo para eles explicarem o tempo todo o que estão falando... [risos] Então tal esforço para entender me 
faz pensar na ilusão que se tem em achar que, pelo facto de estar num contexto onde se fala a mesma língua, se pode compreender tudo. É interessante porque esse é um outro grau de estranhamento que venho enfrentando. Quando você vai fazer uma pesquisa noutro lugar, em geral você tem de enfrentar o aprendizado de uma outra língua. Aqui você não tem, num certo plano, mas num outro tem, à medida que se tem de enfrentar valores e referências culturais desconhecidos. E isso tem sido um aprendizado importante: a possibilidade de enfrentar gradativamente uma série de estranhamentos.

PP Pode falar um pouco mais desta experiência de fazer trabalho de campo em duas cidades tão diferentes e contar alguns episódios...?

HFJ Por exemplo, no caso da pesquisa da Luz, ${ }^{13}$ na cidade onde moro, em que a princípio haveria uma certa familiaridade... Trata-se de um bairro superexposto à mídia, à grande imprensa, por conta de uma série de questões e conflitos, o que passa a impressão de que todos o conhecem. Sinteticamente, há dois aspetos que polarizam o debate: por um lado, a ideia de que a Luz é alvo de uma série de intervenções urbanísticas que vêm acontecendo já há muitos anos por parte do Estado, que quer dotar aquele espaço de instituições culturais e tornar aquilo um "bairro cultural"; na outra ponta dessa polaridade, existe a ideia de que é um bairro degradado. A degradação é uma contrapartida da revitalização. A revitalização e a degradação estão sempre juntas, não é? E um dos aspetos que se frisa muito dessa degradação seria a quantidade significativa de usuários de crack pelas ruas que ajudaram a cunhar o termo "cracolândia" para aquele espaço específico. Então, por um lado, é um bairro conhecido, muito exposto à mídia, e o desafio etnográfico tem sido justamente trazer à tona aspetos não tão visíveis à primeira vista. Quando se lê as notícias, tem-se a impressão de que já se sabe o que está em jogo na Luz. Num certo sentido, essas dimensões estão ali presentes, mas, na pesquisa, temos tentado entender, por exemplo, uma população que mora, que circula por ali e que não aparece nem no discurso da intervenção urbanística, nem no discurso da criminalidade ou do uso das drogas. E nem são necessariamente militantes, embora revelem novas questões políticas. Quer dizer, nos enfrentamentos políticos, as identidades tendem a se polarizar, reforçando-se a ideia de dois mundos em oposição. O que a pesquisa tenta mostrar é que, para além disso, há outras questões nesse entremeio que também devem ser compreendidas. E ali é uma experiência, digamos, mais partilhada de pesquisa. Ou seja, tenho levado adiante essa pesquisa com uma equipe de pesquisadores. Como existem várias dimensões relevantes, tem havido investigações concomitantes. E como

13 Esta pesquisa conta com o apoio do Conselho Nacional de Desenvolvimento Científico e Tecnológico (CNPq). 
são o tempo todo partilhadas, elas ajudam a definir novos rumos, bem como se revelam uma série de conexões.

Vou dar um exemplo. Na Luz, existe um bar chamado "Nova Luz", o que já seria inquietante porque se trata do nome do projeto da prefeitura para revitalizar o bairro. Então como um bar situado quase na área das demolições pode se chamar "Nova Luz"? ${ }^{14}$ Você chega lá e percebe o seguinte: o dono do bar administra uma equipe de futebol amador chamada "Portuguesinha da Luz". Essa equipe foi disputar um campeonato e se ausentou de uma partida, por causa de um grande atraso, o que resultou numa grave eliminação da competição; quando foram participar num novo torneio, tiveram de criar um novo nome e aí foi criada a "Nova Portuguesinha da Luz". E a "Nova Portuguesinha da Luz" virou "Nova Luz"... Bom, essa equipe de futebol, por sua vez, abarca moradores de ocupações da região, organizadas por movimentos sociais, que já tínhamos pesquisado numa outra ocasião. ${ }^{15}$ Então é interessante porque é um nome que parece fazer alusão ao projeto da prefeitura, mas se trata de uma equipe de futebol que conta em boa parte com participantes de movimentos políticos de ocupação da área. Para além disso, há também uma outra coisa interessante. Esse bar quase fora demolido pelos projetos de intervenção. Mas, uma vez que não foi atingido, hoje a área demolida está sendo reconstruída e aí centenas de operários, que ali fazem o trabalho, vão almoçar no bar por conta de um convênio entre o dono e a prefeitura, e tal bar passou a ter um rendimento enorme a partir de então. Numa reflexão polarizada, você ficaria sem referência para compreender a inserção do proprietário desse bar em tal contexto. Porque ele não é nem um militante contra a revitalização - embora tenha relação com os militantes - e também não é um agente do poder público voltado à transformação da área.

Desse modo, na pesquisa da Luz existe uma investigação partilhada onde, na verdade, vão se cruzando uma série de descobertas que levam a certos nós de condensação. Um dos exemplos é o dono desse bar, que é também síndico de um prédio que temos pesquisado. É o exemplo de uma pesquisa que cruza redes mas numa perspetiva intensiva, que se territorializam num certo plano. No caso de Lisboa, é uma experiência diferente...

PP Mais solitária? Mas também encontra, à partida, dois mundos em oposição, que tenta desconstruir...

HFJ Exatamente. Por um lado, ela é solitária, pois se volta um pouco a essa ideia clássica da etnografia de que você articule as várias dimensões observadas

14 As demolições referidas ocorreram em 2007, no âmbito do projeto de intervenção urbanística em questão.

15 As ocupações referidas dizem respeito a edifícios vazios ocupados pelos sem teto (ou sem-abrigo), atores sociais ligados aos movimentos de luta pela habitação, cujas ações levam a embates e negociações com o poder público para a obtenção da casa própria. 
e coloque isso num plano de experiência individual. O que é interessante, por um lado, porque no caso da Luz é preciso trabalhar o tempo todo com as diferenças individuais dos pesquisadores para se criar uma espécie de ethos comum de investigação. No caso do Bairro Alto estou fazendo uma pesquisa, nesse momento, sozinho, embora tenha contado com um auxílio inicial. ${ }^{16}$ Por outro lado, concordo com você que aqui em Lisboa tenho também enfrentado uma certa polarização. No caso do Bairro Alto, o conflito tem outros contornos, mas basicamente a ideia muito veiculada e muito falada pelas pessoas é que o Bairro Alto tem dois mundos, não é? O mundo do dia, dos moradores, com pessoas idosas, principalmente senhoras (demograficamente existem mais mulheres idosas do que homens), e o mundo da noite, que seria o dos bares e do lazer noturno, da boémia, e que seriam mundos em oposição. Claro que existe efetivamente essa dimensão, mas o que chama a atenção na etnografia são justamente as articulações entre esses mundos. Por exemplo, existem senhoras, não aquelas mais velhas, mais doentes, mas as senhoras que, depois de se aposentar, têm em bares uma das suas fontes de trabalho. Ou seja, senhoras que moram no Bairro Alto, que se queixam do barulho noturno e tudo o mais, mas que, por outro lado, trabalham durante muito tempo em bares, na limpeza, durante o dia. A primeira senhora com quem conversei contou que trabalhara na casa de loucos. Eu imaginei que era um tipo de asilo, depois descobri que tinha sido o nome de um bar no Bairro Alto! [risos] Ou então o senhor Nelson, um idoso muito jovial que mora no Bairro Alto mas cujo trabalho é transportar coisas, objetos ou géneros, de um bar para outro. Ele é muito conhecido entre os jovens. Então, na verdade, o que tem aparecido na pesquisa são justamente as conexões entre esses mundos, de certa forma em oposição. Por outro lado, outros tipos de conflito têm-me chamando a atenção. Em 2009, quando fiz uma vinda aqui de mais de três semanas, estava prestes a ser aplicada a lei que ia redefinir o horário do funcionamento noturno dos bares, o que era uma reivindicação já antiga. Então nesse momento o conflito era muito definido pela polaridade moradores versus frequentadores. Eu diria que hoje, dois anos depois, o conflito mais visível ocorre entre os donos dos bares e os donos das lojas de conveniência, em torno da venda de bebidas alcoólicas. Porque hoje existe um fenómeno, a compra em massa da "litrosa", e o botelhão, que é uma palavra inspirada no botellón aliás, é interessante como o Bairro Alto nos anos 80 já era inspirado na movida espanhola... ${ }^{17}$ Aquele fenómeno define também um conflito, não apenas entre

16 Em breve será publicado, numa coletânea organizada pela já citada Rede Brasil-Portugal de Estudos Urbanos, um artigo de Heitor Frúgoli Jr. em parceria com Jessica Sklair, que participou na pesquisa sobre o Bairro Alto nas visitas anteriores, de caráter mais pontual.

17 "Litrosas" são as garrafas de cerveja de um litro, mais baratas para o consumo; "botelhão" refere-se ao consumo coletivo e denso de álcool por grupos juvenis em espaços públicos, que teria a sua origem em Espanha. 
moradores e frequentadores, mas entre aqueles que teriam os bares mais legalizados, com equipamentos e que cobram um determinado preço pela bebida, e esses outros espaços que, num certo sentido, burlariam a lei, venderiam bebidas mais baratas e que levariam a que uma grande população, principalmente jovem, utilizasse o espaço de forma problemática.

LF Centrando-nos agora na experiência da etnografia partilhada na "cracolândia”, que julgo que também envolve alunos seus, gostava muito de saber como se articula a docência e a investigação nessa experiência etnográfica coletiva e qual a sua projeção noutros campos como, por exemplo, o jornalístico. Coloco a hipótese de esse trabalho ter contribuído para a construção de uma imagem alternativa do bairro da Luz...

HFJ Começando por essa última questão que você fez: em geral, abordagens antropológicas dão visibilidade a lugares não muito conhecidos, ou não muito visíveis. Por exemplo, em muitos casos de abordagens de bairros periféricos de São Paulo, era isso que estava em jogo: como é que você dá visibilidade a algo que não é conhecido? No caso da Luz, existe uma overdose de informações a respeito. É difícil você imprimir uma mudança de uma imagem muito consolidada. Então, no caso da Luz, o que tenho às vezes falado na grande imprensa repercute às vezes de forma um pouco estranha, porque procuro dar relevo ao entremeio que existe entre esses mundos, enquanto os jornais muitas vezes querem, na verdade, ressaltar a polarização. E não é só a grande imprensa. Já houve determinados momentos de diálogo, por exemplo, com arquitetos ligados, em São Paulo, ao campo de oposição a certas intervenções urbanísticas, articulados a movimentos populares à esquerda, etc. Quando eles falam da Luz, querem justamente compor um mundo dual: existe o lado de lá, o campo da intervenção urbana, os ricos, o capital imobiliário e tudo o mais, e, do outro lado da trincheira, os movimentos populares, a população, as classes populares, quase como que articuladas contra isso. E as nossas descobertas etnográficas questionam parcialmente isso, mesmo admitindo que existam momentos de radicalização, em que esses processos se polarizam. Nos embates entre o poder público e as populações possivelmente atingidas pelas demolições, têm surgido associações que se colocam contrariamente a esse projeto. Recentemente têm surgido associações de moradores da Luz, que não existiam mas que passa a haver por causa do conflito. O conflito institui certas realidades, dentro de um campo mais complexo de agentes que por vezes não estão ligados nem a um campo, nem ao outro. Eu acho que isso não é de fácil absorção. O conhecimento antropológico sobre a cidade, num certo sentido, concorre com muitos outros. Não tenho expectativas de que a mídia vá levar em conta ou rever essa posição, mas é importante pontuar as diferenças. No caso da Luz, num campo extremamente politizado, é preciso atentar a aspetos para além dessas dualizações. 
Sobre a relação entre docência e investigação, acho que uma pesquisa como essa ajuda, num certo sentido, a definir alguns temas das disciplinas que são ministradas, principalmente na área da antropologia urbana, com a qual trabalho na Universidade de São Paulo. Desse modo, isso delimita certos interesses dos cursos a partir das experiências etnográficas de pesquisa.

Mas na pesquisa sobre a Luz só participam orientandos, não alunos. E o enfrentamento etnográfico dos usuários de crack acabou por ser feito apenas pelo Enrico, um dos antropólogos que fazem parte dessa equipe, e por mim. ${ }^{18}$ Nesse caso, como era um trabalho que envolvia uma aproximação delicada, acabou por ser uma investigação mais restrita quanto à participação de outras pessoas, embora os temas tratados fossem cruzados com o que era pesquisado pelos outros.

PP O seu trabalho Espaços Públicos e Interação Social, um livro sobre São Paulo, faz referência a "uma tendência", e estou a citar, "para a redução considerável da diversidade e heterogeneidade dos espaços de interação social interclasses". Gostaríamos de saber se também encontra esta tendência em Lisboa e como é que ela se declina.

HFJ Penso que essa afirmação hoje merece certa relativização. Nesse livro, em 1995, eu estava mais permeável à ideia de que haveria uma espécie de desertificação de boa parte dos espaços públicos, com o reforço do controle, e que isso levaria, num certo sentido, a uma diminuição da diversidade. Hoje revejo essa ideia, bastante discutida na época, de uma cidade muito apartada. O trabalho de Teresa Caldeira, ${ }^{19}$ por exemplo, caminhava muito nessa direção, ao falar que São Paulo é uma cidade de muros, uma cidade apartada, uma cidade onde haveria na verdade uma crescente separação entre os mundos sociais. Eu concordava parcialmente com esse argumento. Hoje vejo de uma outra forma. Acho que mesmo os condomínios fechados implicam relações, interações, que estão presentes mesmo quando aparentemente não estariam. Por exemplo, Jessica Sklair foi minha orientanda de mestrado, quando ela pesquisou justamente a relação de grupos ligados às classes de maior poder aquisitivo na região do Morumbi e os projetos filantrópicos voltados a regiões carentes - sua pesquisa resultou num livro chamado A Filantropia Paulistana..$^{20}$ O interessante é que ela mostra que nesse campo entre pobreza e riqueza, na

18 Heitor Frúgoli Jr. e Enrico Spaggiari, 2010, "Da cracolândia aos noias: percursos etnográficos no bairro da Luz", Ponto Urbe, 6, http://www.pontourbe.net/edicao6-artigos/l 1 8-da-cracolandia-aos-noias -percursos-etnograficos-no-bairro-da-luz.

19 Teresa Caldeira, 2000, Cidade de Muros: Crime, Segregação e Cidadania em São Paulo, São Paulo, Edusp/Ed. 34.

20 Jessica Sklair, 2010, A Filantropia Paulistana: Ações Sociais em Uma Cidade Segregada, São Paulo, Humanitas/Fapesp. 
verdade, existe muita interação, muita relação. Em geral tratamos como se fossem mundos totalmente separados. Eu tendo a achar hoje que essa é uma questão frutífera do ponto de vista das abordagens etnográficas. Eu não tomaria o pressuposto da separação, mas, do ponto de vista de uma relação, mesmo que ela seja conflitiva, assimétrica.

GIC O trabalho do antropólogo na cidade passa muito por uma tentativa de localizar e encontrar as suas unidades de observação, com todo um trabalho de focalização. Nesta dupla inserção em Lisboa, por um lado, a focalizares-te num problema, num objeto e num bairro, e há já bastantes meses a viver em Lisboa, como é que vês o trabalho do antropólogo urbano noutra cidade? Achas que o tempo de estadia é importante para agarrar o ambiente urbano, o seu ethos?

HFJ Eu vou dar exemplos da própria etnografia. Por exemplo, o facto de eu estar aqui há algum tempo permite que eu acompanhe algumas pessoas que eu contactei em situações específicas. Quando comecei o trabalho de campo, conheci uma artista plástica que tinha tido uma relação forte com a Galeria Zé dos Bois, circulou muito nesse espaço específico, mas que vinha pensando na crise em Portugal e, ao mesmo tempo, na crise ambiental, o que a levou a pensar num projeto de morar fora da cidade. Bom, interessante que eu recentemente a encontrei e ela realmente tinha feito isso. Quando você fica um tempo maior, você acompanha melhor as trajetórias. Uma outra coisa que eu acho importante: você passa a entender melhor os termos que são falados, as palavras... Algumas coisas incompreensíveis num primeiro momento vão-se tornando mais familiares. Você passa a entrar em contacto com algumas expressões, com significados que só com o tempo se pode adquirir. Por outro lado, acho que isso também traz novas questões. O facto de você ficar em Lisboa - eu estou aqui há alguns meses - dá a ilusão de que "Ah, bom! Eu me sinto lisboeta..." [risos] Então, na Semana Santa, por exemplo, o que se falava é que no Bairro Alto e na cidade viriam muitos turistas espanhóis. Eu estava aqui nessa semana, num bar ali no largo de Camões e realmente muitos dos clientes eram espanhóis, ingleses, pedindo coisas... E o rapaz do balcão falou ironicamente: "Vou precisar fazer curso de espanhol e curso de inglês para entender essas pessoas..." Aí, eu falei com ele: "Pois é, tem muito gringo..." [risos] Aí ele falou: "Inclusive brasileiros!" [risos] Então, na verdade, acho que a relação entre familiaridade e estranhamento coloca-se o tempo todo como uma questão. $\mathrm{O}$ facto de poder estar mais tempo aqui permite perceber certas regularidades e como essa dimensão se impõe aos poucos como tema. O facto de estar mais tempo aqui vai-me fazendo perceber certas questões que numa visada mais rápida talvez eu nem me desse conta, ou nem percebesse que fossem temas importantes. Não sei se isso responde exatamente ao que você perguntou. Por outro lado, acho também que toda construção, toda definição de 
um objeto implica a construção de um determinado espaço e de situações que são também um problema teórico. No Bairro Alto eu consegui definir algumas ruas ou espaços onde posso fazer uma observação mais recorrente, onde em geral eu não entrevisto, eu não pergunto. Na verdade, eu interajo.

GIC Eu estava a tentar identificar aquilo que é o contexto urbano ou o contexto comunicacional de uma cidade, coisas que são difíceis de definir.

HFJ Com certeza. Eu consegui, no Bairro Alto, acompanhar etnograficamente os ensaios e a apresentação dos integrantes das marchas populares desse ano, o que acabou também por ser um esforço gradativo de aproximação. Eu tinha definido uma estratégia de aproximação no começo que não resultou, só depois de várias tentativas e alguns acasos. Mas é claro que essa observação ficou muito enriquecida pelo facto de eu poder acompanhar também em Lisboa a conceção, por exemplo, da Câmara Municipal sobre as festas populares, sobre os eventos que tomam parte dessa festa, eventos que se entende não serem apenas populares mas também voltados à apresentação de Lisboa a um contexto mais abrangente, e assim compreender como esses temas se articulam. De modo que acho que isso me ajuda a situar algo mais abrangente. $\mathrm{O}$ que faz com que Lisboa acabe por se tornar também objeto da pesquisa, mas não numa perspetiva totalizante de tentar entender a cidade como um todo, mas em que medida Lisboa pode emergir a partir daquilo que venho observando. Vou dar outro exemplo: o Rossio, há um mês e meio, como vocês sabem, se tornou um espaço de uma manifestação política muito interessante. ${ }^{21}$ Certo dia eu encontrei ali um rapaz que estava no meu rol de relações de pesquisa, o que me despertou um novo interesse. Para além do evento em si, que é importante, se tornou também significativo ver como essa pessoa entrava ali, a participação dela...

GIC As redes...

HFJ Exatamente. Eu acho que o esforço tem sido ver como é que, a partir dessa pesquisa, ela se abre para outros aspetos também relevantes.

\section{LF E para outros espaços...}

HFJ E para outros espaços, sem dúvida. E isso aparece de muitas formas, inclusive como o próprio espaço do Bairro Alto é ressignificado pelos agentes.

21 Em maio de 2011 , a praça foi ocupada por dezenas de jovens, vários deles ali acampados, em aparente diálogo com um movimento que ganhara forte visibilidade em Espanha, como protesto dirigido ao capitalismo, ao sistema político, à falta de perspetivas acarretada pela crise europeia, etc. 
Estava comentando agora há pouco com a Patrícia como, por exemplo, a ladeira da Bica, a ladeira do funicular, como é o nome...?

GIC Rua da Bica de Duarte Belo.

HFJ Exato. Como é um espaço de crescente utilização de lazer e para alguns agentes aquilo é significado como...

PP Uma extensão?

HFJ Como uma extensão do Bairro Alto. É intrigante... Mas por que seria uma extensão do Bairro Alto e não um espaço da própria Bica? Existem, por exemplo, alguns bares no Bairro Alto, como o "Maria Caxuxa", ou o "Majong", esse mais no passado, frequentados por pessoas ligadas à classe artística, que também têm frequentado alguns bares da Bica, como o "Funicular" e outros. E eles definem entre eles essa articulação. Então, o espaço do próprio Bairro Alto vai se redefinindo. Inicialmente, eu achava que essas fronteiras estavam mais nítidas, em comparação com São Paulo. Por exemplo, se você olha certos guias do Bairro Alto ou o livro de Helder Carita, ${ }^{22}$ aquela delimitação é muito categórica, não é? Mas recentemente eu estava numa reunião de preparação de eventos para o próximo aniversário do Bairro Alto e tinha uma senhora que, para ela, a calçada do Combro, lá em baixo, na Santa Catarina, aquilo é Bairro Alto. Quer dizer, ela tinha uma outra definição. Hoje inclusive vou fazer uma fala na livraria "Círculo das Letras" e o cartaz que prepararam para a minha fala tem a escada da Bica...

GIC Mas tem as escadinhas, não tem a rua da Bica de Duarte Belo. Isso faz a diferença...

HFJ Claro. Existe também uma dimensão que tem-me chamado a atenção mais recentemente. Por exemplo, em 2007 eu tinha visitado a Cova da Moura através de um grupo que apresentava tal bairro para as pessoas de fora. Era uma ONG local, ligada ao Moinho da Juventude, com um jovem que fazia uma espécie de apresentação com um discurso político. Mais recentemente o Bairro Alto, que não estaria na alçada dos bairros sociais, tem uma ONG também, a + Skillz, situada lá e que também faz roteiros para apresentar às pessoas "o verdadeiro" Bairro Alto, com um discurso que, num certo sentido, tenta produzir uma espécie de essencialização: "Nós hoje vamos apresentar o verdadeiro Bairro Alto, vamos ver os moradores, o comércio local e tudo o mais..."

22 Helder Carita, 1994, Bairro Alto: Tipologias e Modos Arquitectónicos, Lisboa, Câmara Municipal de Lisboa. 
Interessante como você tem hoje ali uma certa agenda de apresentar o bairro para a população. Então há esse desafio de cruzar um conjunto multifacetado de representações sobre esse espaço.

GIC Uma última pergunta. Situando-nos no espaço da antropologia urbana em língua portuguesa, eu considero que a tua vinda a Lisboa ajuda a criar uma ponte muito importante entre a antropologia urbana brasileira e a portuguesa ao nível da investigação comparada, das colaborações, diálogo, algo coletivo, em conjunto. Esta ponte não é nada óbvia, apesar das supostas facilidades linguísticas. Pergunto-te como te situas, como é que vês esta colaboração. Tenho de relembrar que esta mesma revista, a Etnográfica, publicou no seu primeiro ano de vida, em 1997, uma entrevista a Gilberto Velho, que foi uma das pessoas que mais ajudou a desenvolver esta relação luso-brasileira. ${ }^{23}$ Estamos em 2011 e muitas pequenas coisas foram feitas neste âmbito...

HFJ Acho importante poder fazer parte de um campo de interlocução entre Brasil e Portugal, que está em construção e do qual vocês também fazem parte. Bom, a antropologia urbana no Brasil se institucionalizou um pouco antes de isso acontecer em Portugal, não é? Quer dizer, nos anos 70 isso já vinha se articulando, primeiramente no Rio e em São Paulo e depois noutros centros. O que está acontecendo mais recentemente é uma intensificação desses intercâmbios. Se a gente mapear, por exemplo, aqui em Lisboa, a vinda do Gilberto Velho - que representa, num certo sentido, muito da antropologia urbana carioca... - e depois a vinda do José Guilherme Magnani, a convite de vocês, então eu acho que isso tem criado uma espécie de campo de interlocução a partir do qual, num certo sentido, eu já me sinto beneficiado. Talvez exista uma contribuição minha, em parte por fazer aqui uma etnografia mais a longo prazo. Se isso ajuda, num certo sentido, a estabelecer uma ponte, do ponto de vista não apenas teórico, mas que também passe pela pesquisa, fico muito contente. E acho que o próprio esforço que a Graça fez de traduzir o livro do Michel Agier - que envolveu também a participação do Magnani e minha na revisão conceptual, para além de ter ocorrido aqui também o seu lançamento, com debate - também ajuda no fortalecimento dessas relações. Eu fico contente por poder participar de um campo que está em construção e espero que essa interlocução possa aumentar. 